\title{
Entrevista a Guillermo Ulriksen Becker sobre el Plan Constructivo La Serena - Coquimbo, en 1952.
}

\section{J. Torres Valencia}

Desde la salida de la estación de ferrocarril hasta la entrada a la ciudad, lugar que hasta hace cinco años estaba sólo constituido por vegas pantanosas, ha sido sabiamente aprovechado y convertido en uno de los parques más hermosos existentes en el país.

Este parque fue proyectado por el conocido arquitecto paisajista Oscar Prager y su realización ejecutada por el ingeniero agrónomo señor Juan Alemparte.

La desecación de los puntos pantanosos en esta zona ha estado a cargo del Departamento de Riego, de Vías y Obras, desde Coquimbo, del lugar llamado Estero del Culebrón hasta el río Coquimbo que es el límite norte de La Serena, trabajos que se ejecutan por canales en lo agrícola, y en lo urbano por tubos subterráneos de 80 centímetros de diámetro.

Las aguas de desecación se han aprovechado para regadíos agrícolas y del parque mismo.

A lo largo del parque, entre la estación y la ciudad, pasaba el antiguo camino longitudinal que en este sector está siendo mejorado con el financiamiento especial que corresponde a la Carretera Panamericana. En esta forma, los bajos del camino que eran de 20 metros, se están ensanchando a 40 metros a lo largo de la Carretera, pero entre la ciudad de Coquimbo y La Serena, la calzada tiene 65 metros de ancho.

Fuera del ensanche de la faja de tierra, que se ha hecho ampliar el pavimento que era antes de 5 1/2 metros, ha quedado de 7 metros.

El progreso notorio que se observa en La Serena, es la pavimentación de todas sus calles, trabajos que se han realizado con todo éxito y con los recursos ordinarios.

Los urbanistas [Arqto. Guillermo Ulriksen B. ${ }^{1}$ ] estiman que esta es una obra netamente sanitaria, especialmente en estas ciudades del norte donde la tierra abunda por la sequía de los campos.

En cuanto a áreas verdes se refiere, además del parque, obtenido por desecación de un pantano, se ha logrado darle un aspecto atrayente al antiguo paseo municipal del cerro Santa Lucía y esto, gracias a un expediente sencillo: haber entregado el cerro al Regimiento que se encuentra instalado en él. Además, los herederos de don Gabriel Coll Dalmau donaron a la ciudad un fundo adyacente a ella de 60 hectáreas con sus derechos de regadío, lo que ha permitido plantar varios miles de árboles y arbustos chilenos: quillay, peumo, pino marítimo, olivo, laurel de flor, etc., que han resultado ser muy resistentes a la relativa escasez de agua para el riego.

En el aspecto de la vivienda, el éxito obtenido en cinco años de labor -al lograr levantar habitaciones de carácter permanente y asísmicas para la quinta parte de la

\footnotetext{
${ }^{1}$ Señaló el Arqto. Guillermo Ulriksen B., en una cita bibliográfica en su tesis de título de Arquitecto (Bases Para la Planeación Regional del Norte Chico: Provincias de Atacama \& Coquimbo: Región de los Valles Transversales, Facultad de Arquitectura, Universidad de Chile, 1952), que él fue el entrevistado en la ocasión, pero que el periodista no lo mencionó en el escrito que presentamos.
} 
población de la ciudad-, se debe en forma exclusiva a dos factores: la capacidad coordinadora del Poder Ejecutivo y la existencia de una ley de expropiaciones operativa (la de la Corporación de Reconstrucción).

El poder coordinador logró aumentar la capacidad constructiva de cada una de las instituciones de Previsión de Chile, o sea, Cajas de los Empleados Particulares, Montepío de Carabineros, Caja de Previsión de los Ferroviarios, Empleados de la Caja de Ahorros y hasta de la Caja de la Habitación.

Las instituciones de previsión están construyendo en La Serena viviendas definitivas en serie para una parte de sus imponentes, y la Caja de la Habitación cerca de mil viviendas de dos piezas para las familias obreras, no afectas a instituciones de previsión capaces de construir.

Como complemento de este gran volumen de viviendas definitivas el Poder Ejecutivo ha logrado paralelamente construir también locales escolares resistentes a los terremotos (que es la peor amenaza latente y permanente para la población urbana del país). En resumen, estas obras estas obras están inspiradas principalmente en la seguridad colectiva que tiene sus raíces en la historia del terremoto de Chillán.

Con respecto a la producción, La Serena es la capital de una provincia en que predomina la renta agrícola. En segundo lugar, le corresponde la renta minera y, en tercero, la industrial. De ahí que no se plantea en La Serena la constitución de un barrio industrial propiamente dicho y existe la tendencia de la industria incipiente a radicarse en la ciudad de Coquimbo que es el centro ferroviario, caminero y portuario.

Coquimbo tiene un potencial económico, prácticamente igual al potencial económico de La Serena, pero este potencial se expresa de distintas maneras. Coquimbo tiende a lo industrial y La Serena a lo educacional.

Las grandes inversiones de dineros fiscales en la provincia de Coquimbo han sido hechas en la Estación de Guayacán y en el molo del puerto de Coquimbo, en cambio, en La Serena, sus inversiones principales son las efectuadas por las Cajas de Previsión.

Por otra parte, las inversiones de carácter educacional en La Serena han sido hechas por la Sociedad de Establecimientos Educacionales.

[Fotografías que acompañan la entrevista]: 

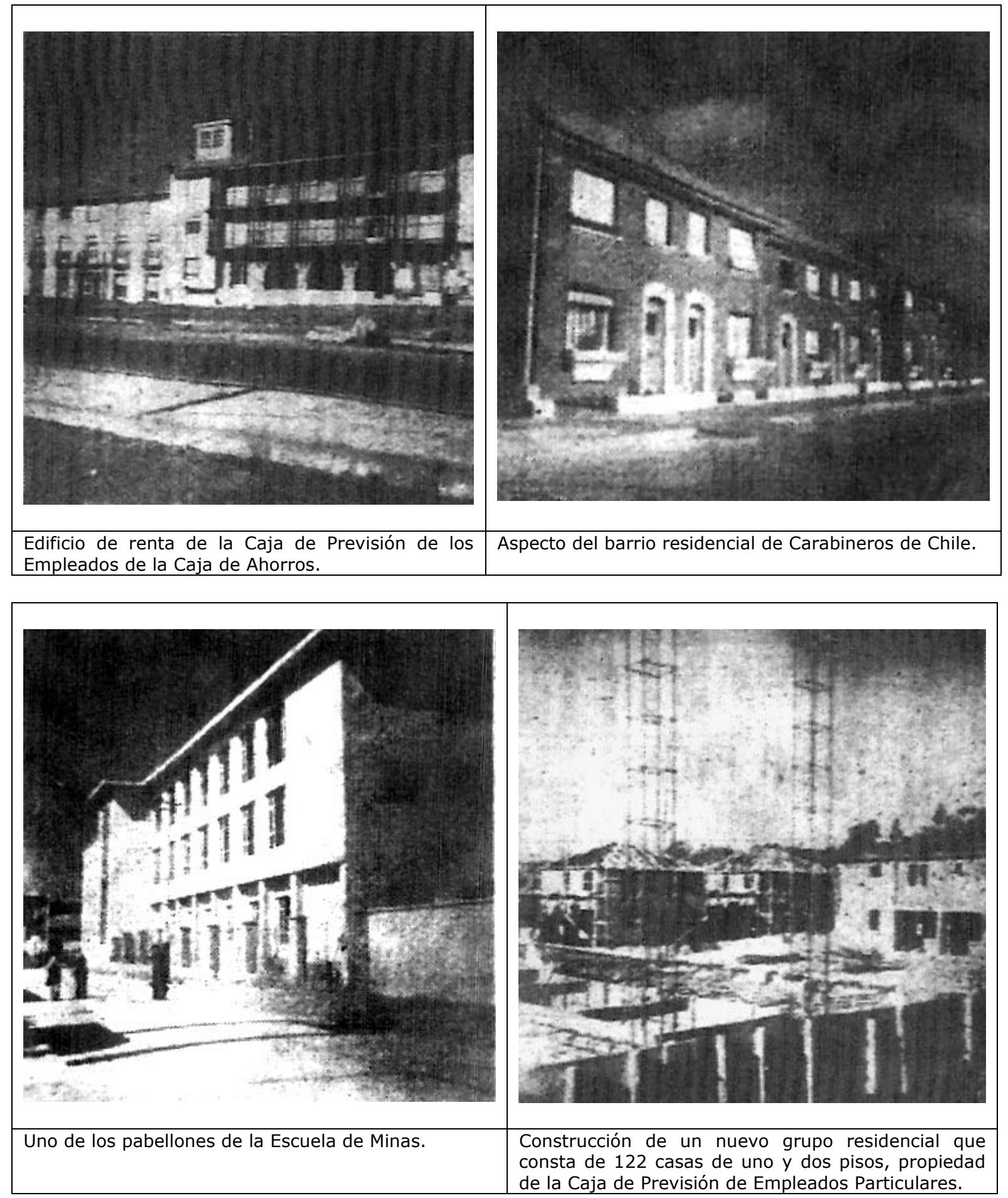

Fte.: EI Mercurio, Santiago de Chile, 7 de marzo de 1952, p. 27. 